\title{
СОПОСТАВЛЕНИЕ ДИНАМИКИ И УСТОЙЧИВОСТИ РАЗВИТИЯ ПРОИЗВОДСТВА ЗЕРНА ПО РЕГИОНАМ РОССИИ
}

\author{
(c) 2018 Зюкин Данил Алексеевич \\ кандидат экономических наук \\ Курский государственный университет \\ 305000, г. Курск, улица Радищева, 33 \\ E-mail: nightingale46@rambler.ru
}

В статье рассматривается проблема рационального территориального размещения производства зерна по стране. В исследовании выполнен анализ динамики и устойчивости производства зерна в субъектах РФ. Выявлено, что наиболее устойчивым рост урожаев зерна был в Краснодарском крае, в Кабардино-Балкарской республике и Красноярском крае, а самая высокая динамика в относительном выражении - в Брянской области (в 4,2 раза), в Кабардино-Балкарской Республике (в 2,8 раза), в Курской и Орловской областях (2,5 раза). В статье представлены направления, реализация которых будет способствовать рациональному территориального размещению и устойчивости производства зерна, а также повышению эффективности бизнес-субъектов всей цепочки зернопродуктового подкомплекса АПК.

Ключевые слова: зернопродуктовый подкомплекс АПК, производство зерна, продовольственная безопасность, рост урожаев зерна, производство зерна на душу населения, устойчивость производства.

Зернопродуктовый подкомплекс является системообразующим элементом АПК, от уровня развития которого зависит продовольственная независимость страны. Основой зернопродуктового подкомплекса АПК является производство зерна, поэтому оно имеет очень широкую географию. В 2016 году в России возделыванием зерновых занимались в 75 из 85 регионов, при этом урожаи свыше 100 тыс. т зерна получены в 60 регионах. Наибольшая доля урожаев зерновых приходится на регионы Южного федерального округа (27\%), обладающими наилучшими природно-климатическими условиями, однако показатели Центрального и Поволжского федеральных округов - 23,1 и 20,3\% вполне сопоставимы. Даже в округах с крайне тяжелыми условиями производства осуществляется возделывание зерна - в Дальневосточном собрано более 800 тыс. т, а в Северо-Западном - более 900 тыс. т. зерна. Все это подчеркивает значимость производства зерна для стабильного социально-экономического положения страны и необходимость его осуществления даже в географических зонах с неблагоприятными природно-климатическими условиями.

Зерновое хозяйство является одним из основных в структуре сельскохозяйственного производства многих регионов, поэтому урожаи зерновых свыше 1 млн. т удалось собрать в 31 ре- гионе страны, а в 15 из них урожаи превысили 3 млн. т, что свидетельствует о высоконцентрированном и результативном производстве зерна в них. Отдельно следует отметить Краснодарский край, Ростовскую область и Ставропольский край, которые традиционно считаются аграрной житницей России, где урожаи зерна превысили 10 млн. т. (табл. 1). Помимо сравнительно более благоприятных природно-климатических условий на активизацию производства зерна в этих субъектах РФ оказывает влияние их географическое положение, предопределяющее их экспортную ориентированность.

Валовые сборы зерна за десятилетие с начала реализации Нацпроекта увеличилось более чем на 40 млн. т, поэтому для выработки направлений рационального территориального размещения посевов зерновых важно оценить произошедшие изменения в производстве зерна на уровне регионов. Для такой оценки нами проведен анализ изменений производства зерна по субъектам РФ, в которых оно имеет высокую концентрацию посевов, что позволяло получать урожаи свыше 1 млн. т. Относительно 2006 года только в 5 из 30 регионов валовой сбор зерновых в 2016 году сократился. Причем, лишь в Республике Башкортостан проблема сокращение производства зерна значима, в то время как в Нижегородской, Тюменской, Челябинской об-

* Статья подготовлена при финансовой поддержке РФФИ в рамках научного проекта № 18-310-00211 
Таблица 1. Группировка субъектов РФ по величине урожая зерновых в 2016 году

\begin{tabular}{|c|c|}
\hline Группа & Перечень регионов в группе (валовый сбор зерновых, тыс. т) \\
\hline $\begin{array}{l}\text { Регионы с незначительным } \\
\text { объемом производства зерна, } \\
\text { менее } 100 \text { тыс. т }\end{array}$ & $\begin{array}{l}\text { Входит } 15 \text { регионов: Ярославская область (85), Забайкальский край (80), } \\
\text { Костромская область (54), Новгородская область (52), Республика Бурятия } \\
\text { (33), Астраханская область (29), Республика Саха (12), Хабаровский край } \\
\text { (12), Республика Алтай (10), Еврейская автономная область (9), Республика } \\
\text { Тыва (9), Москва (6), Архангельская область (5), Севастополь (2). }\end{array}$ \\
\hline $\begin{array}{l}\text { Регионы с малым уровнем } \\
\text { валовых сборов зерна от } 100 \text { до } \\
500 \text { тыс. т) }\end{array}$ & $\begin{array}{l}\text { Входит } 20 \text { регионов: Амурская область (475), Карачаево-Черкесская респу- } \\
\text { блика (471), Калининградская область (400), Республика Дагестан (376), } \\
\text { Московская область (358), Чеченская республика (307), Томская область } \\
\text { (304), Приморский край (297), Пермский край (247), Смоленская область } \\
\text { (233), Вологодская область (223), Республика Марий Эл (214), Владимирская } \\
\text { область (203), Калужская область (156), Ивановская область (126), Респу- } \\
\text { блика Хакасия (122), Ленинградская область (117), Псковская область (117), } \\
\text { Республика Ингушетия (111), Тверская область (100). }\end{array}$ \\
\hline $\begin{array}{l}\text { Регионы со средним уровнем } \\
\text { валовых сборов от } 100 \text { до } 500 \\
\text { тыс. т }\end{array}$ & $\begin{array}{l}\text { Входит } 9 \text { регионов: Кемеровская область (938), Иркутская область (772), Ре- } \\
\text { спублика Адыгея (700), Чувашская Республика (609), Республика Северная } \\
\text { Осетия - Алания (608)ши, Свердловская область (597), Удмуртская Респу- } \\
\text { блика (542), Кировская область (527), Республика Калмыкия (500). }\end{array}$ \\
\hline $\begin{array}{l}\text { Регионы высокими урожаями } \\
\text { зерна, от } 1 \text { до } 3 \text { млн. т }\end{array}$ & $\begin{array}{l}\text { Входит } 16 \text { регионов: Липецкая область (2877), Красноярский край (2354), } \\
\text { Новосибирская область (2341), Самарская область (2119), Челябинская } \\
\text { область (1948), Пензенская область (1944), Курганская область (1813), } \\
\text { Рязанская область (1555), Тульская область (1555), Брянская область (1439), } \\
\text { Республика Крым (1287), Тюменская область (1286), Республика Мордовия } \\
\text { (1192), Ульяновская область (1187), Кабардино-Балкарская Республика } \\
\text { (1150), Нижегородская область (1128). }\end{array}$ \\
\hline $\begin{array}{l}\text { Регионы с высокой концентра- } \\
\text { цией урожаев зерна, превыша- } \\
\text { ющих } 3 \text { млн. т }\end{array}$ & $\begin{array}{l}\text { Входит } 12 \text { регионов: Алтайский край (4830), Воронежская область (4817), } \\
\text { Волгоградская область (4524), Курская область (4380), Саратовская область } \\
\text { (4259), Республика Татарстан (4105), Белгородская область (3506), Респу- } \\
\text { блика Башкортостан (3324), Омская область (3268), Тамбовская область } \\
\text { (3250), Оренбургская область (3134), Орловская область (3131). }\end{array}$ \\
\hline $\begin{array}{l}\text { «Лидеры» } \\
\text { (свыше } 10 \text { млн. т) }\end{array}$ & $\begin{array}{l}\text { Входит } 3 \text { региона: Краснодарский край (13979), Ростовская область (11596), } \\
\text { Ставропольский край (10250). }\end{array}$ \\
\hline
\end{tabular}

Источник. Составлено автором на основе данных статистического сборника Регионы России [3]

ластях и Республике Татарстан сокращение оказалось конъюнктурного характера. Наибольший прирост в абсолютном выражении показали три лидера по объемам валовых сборов зерна: Краснодарский край - 5,7 млн. т, Ростовская область - 5,3 млн. т и Ставропольский край - почти 4 млн. т. В относительном выражении в ряде регионов урожаи увеличились в несколько раз: в Брянской области - в 4,2 раза; в Кабардино-Балкарской Республике - в 2,8 раза; в Курской и Орловской областях - 2,5 раза; в Воронежской - в 2,3 раза; в Белгородской и Тульской областях - в 2,1 раза. Особо следует отметить успехи, которые достигли области Центрально-Черноземного региона, где все субъекты повысили урожаи зерна более чем на 1 млн. т, а лучшими среди них стали Воронежская область - на 2762 тыс. т и Курская область - на 2648 тыс. т. (таблица 2).

При этом о развитии производства зерна следует судить не только по наращиванию урожаев, но и по устойчивости этого процесса. Устойчивость увеличения урожаев мы предла- гаем оценивать на основе регрессионного метода, в рамках которого строится линейный тренд для описания вариации валового сбора зерна, а относительная ошибка аппроксимации характеризует насколько устойчивым были фактические результаты относительно построенной модели. В период 2006-2016 гг. наиболее высокий уровень устойчивости выявлен в Краснодарском крае - относительная ошибка аппроксимации модели тренда составила 7,2\%. Менее 10\% показатель только в Кабардино-Балкарской Республике $(7,9 \%)$ и Красноярском крае $(8,1 \%)$, в то время как в большинстве субъектов РФ относительная ошибка аппроксимации оказалась выше 15\%, что с точки зрения математической оценки модели свидетельствует о невысоком ее качестве [2, 5]. Поэтому следует признать, что урожаи зерна во многих регионах страны имеют неустойчивый характер, что является весьма серьезной проблемой для развития зернопродуктового подкомплекса АПК.

Не смотря на проблемы с устойчивостью 
Таблица 2. Изменение валовых сборов зерна в субъектах РФ в 2006-2016 гг.

\begin{tabular}{|c|c|c|c|c|}
\hline \multirow{2}{*}{ Регионы РФ } & \multicolumn{2}{|c|}{ Годы } & \multicolumn{2}{|c|}{ Изменение } \\
\hline & 2006 & 2016 & тыс. т & $\%$ \\
\hline Краснодарский край & 8239,1 & 13979 & 5740 & 69,7 \\
\hline Ростовская область & 6309,8 & 11595,8 & 5286 & 83,8 \\
\hline Ставропольский край & 6271,2 & 10249,9 & 3979 & 63,4 \\
\hline Воронежская область & 2055,1 & 4817,3 & 2762 & 134,4 \\
\hline Курская область & 1731,8 & 4379,8 & 2648 & 152,9 \\
\hline Орловская область & 1268 & 3131 & 1863 & 146,9 \\
\hline Белгородская область & 1645,9 & 3505,6 & 1860 & 113,0 \\
\hline Тамбовская область & 1701,2 & 3250,4 & 1549 & 91,1 \\
\hline Алтайский край & 3519,5 & 4829,7 & 1310 & 37,2 \\
\hline Волгоградская область & 3334,7 & 4524,4 & 1190 & 35,7 \\
\hline Липецкая область & 1721,4 & 2877,2 & 1156 & 67,1 \\
\hline Оренбургская область & 2019,3 & 3133,9 & 1115 & 55,2 \\
\hline Брянская область & 340,4 & 1439,1 & 1099 & 322,8 \\
\hline Красноярский край & 1479 & 2353,5 & 875 & 59,1 \\
\hline Самарская область & 1251,5 & 2119,4 & 868 & 69,3 \\
\hline Саратовская область & 3411,3 & 4258,6 & 847 & 24,8 \\
\hline Пензенская область & 1107,9 & 1943,9 & 836 & 75,5 \\
\hline Тульская область & 742,8 & 1554,8 & 812 & 109,3 \\
\hline Кабардино-Балкарская Республика & 411,1 & 1150,3 & 739 & 179,8 \\
\hline Рязанская область & 935,9 & 1554,8 & 619 & 66,1 \\
\hline Новосибирская область & 1761,2 & 2341,1 & 580 & 32,9 \\
\hline Ульяновская область & 726,6 & 1187,1 & 461 & 63,4 \\
\hline Курганская область & 1426,3 & 1813,2 & 387 & 27,1 \\
\hline Омская область & 2890,6 & 3267,7 & 377 & 13,0 \\
\hline Республика Мордовия & 945,7 & 1192,4 & 247 & 26,1 \\
\hline Нижегородская область & 1165,9 & 1127,5 & -38 & $-3,3$ \\
\hline Тюменская область & 1345,5 & 1286,4 & -59 & $-4,4$ \\
\hline Республика Татарстан & 4164,5 & 4105,2 & -59 & $-1,4$ \\
\hline Челябинская область & 2120,5 & 1947,7 & -173 & $-8,1$ \\
\hline Республика Башкортостан & 3883,3 & 3324 & -559 & $-14,4$ \\
\hline
\end{tabular}

Источник. Составлено автором на основе данных статистического сборника Регионы России [3]

урожаев, динамичное увеличение валовых сборов позволило приблизиться к решению важной стратегической задачи развития зернового хозяйства - стабильное производство одной тонны зерна на душу населения. Такой объем производства позволит повысить внутреннее потребление зерна на цели импортозамещения, увеличить доходность его производителей, а также значительно укрепить экспортные позиции России в мире $[1,4]$. Согласно же Концепции долгосрочного социально-экономического развития Российской Федерации в 2020 г. производство зерна в расчете на душу населения должно составить 869-905 кг. В период 2012-2016 гг. происходит динамичное увеличение этого пока- зателя, но его значение пока все равно меньше (табл. 3).

Для достижения такого значения необходимо нарастить производство зерна до 145-150 млн. т, чего можно добиться за счет ввода в сельскохозяйственный оборот до 5-10 млн. га заброшенных земель или при доведении урожайности до 31,4 ц/га. Однако оба варианта труднодостижимы в текущих условиях. Более того, внутренний рынок зерна даже в условиях реализации программы импортозамещения увеличивается медленно, поэтому избыточное производство может привести к неблагоприятной ценовой конъюнктуре на зерновом рынке, в результате чего основными пострадавшими будут зерно- 
Таблица 3. Производство зерна в расчете на душу населения в России в 2012-2016 гг.

\begin{tabular}{|l|c|c|c|c|c|c|}
\hline \multicolumn{1}{|c|}{ Показатели } & 2012 г. & 2013 г. & 2014 г. & 2015 г. & 2016 г. & Изменение,\% \\
\hline Численность населения, тыс. чел. & 143347 & 143667 & 146267 & 146545 & 146804 & 2,4 \\
\hline Валовой сбор, млн. т & 70,9 & 92,4 & 105,3 & 104,8 & 120,7 & 70,2 \\
\hline $\begin{array}{l}\text { Производство зерна в расчете на } \\
\text { душу населения, кг }\end{array}$ & 495 & 643 & 720 & 715 & 822 & 66,2 \\
\hline
\end{tabular}

Источник. Составлено автором на основе данных статистического сборника Регионы России [3]

производители. Уже сейчас за счет экспорта с внутреннего рынка санируется свыше 30 млн. т, а в 2017 году был побит рекорд - экспорт составил 43,3 млн. т, поэтому достижение производства одной тонны зерна на душу населения должно реализовываться только в совместных мероприятиях, позволяющих расширить емкость внутреннего рынка.

Дефицит зерна, который возникает в стране на локальных рынках, следует решать путем улучшения межрегионального обмена зерном. Сейчас существует колоссальная разница в обеспечении зерном в разных субъектах РФ. Совершенно понятно, что Москва и Санкт-Петербург, самостоятельно обеспечить себя зерном не могут в силу очевидных причин. Однако существует значительное число регионов, где условия не позволяют осуществлять возделывание зерна совсем, либо этих урожаев категорически недостаточно для обеспечения потребностей в производстве продовольствия. С другой стороны, в стране 25 регионов, где производится зерна свыше одной тонны на душу населения. Причем, в Курской и Орловской областях этот показатель находится в районе 4 тонн, а Ставропольском крае и Тамбовской области превышает 3 тонны (табл. 4).

Учитывая широкий перечень территориальных зон, в которых существует переизбыток производства зерна, нужно осуществлять реализацию направлений, которые будут спо- собствовать рациональному территориальному размещению производства зерна. Для этого важно разработать единую стратегию развития зернопродуктового подкомплекса АПК, в которой будет сформированы положения, которые позволят комплексно решить не только вопросы рациональное размещение производства зерна и полного удовлетворения спроса на него, но и повысить эффективность непосредственных зернопроизводителей. Важными положениями такой стратегии должны стать направления, позволяющие добиться решения следующих задач:

- улучшить размещение и усилить концентрацию производства зерна в регионах с благоприятными агроклиматическими условиями, позволяющими обеспечить максимальную реализацию экономико-технологических факторов;

- сократить случаи избыточной концентрации, когда доля зернового клина превышает 60$65 \%$, не обеспечивая реализации естественных агротехнологических преимуществ применения оптимального севооборота;

- углубить специализацию возделывания дефицитных видов зерновых культур и высококачественной пшеницы;

- способствовать сокращению технологического разрыва между агропроизводителями для повышения устойчивости производства зерна и активизации процессов интенсификации;

- обеспечить рациональное использование

\section{Таблица 4. Производство зерна на душу населения в регионах РФ в 2016 году}

\begin{tabular}{|l|l|}
\hline \multicolumn{1}{|c|}{ Производство зерна } & \multicolumn{1}{|c|}{ Перечень регионов в группе (показатель, кг) } \\
\hline $\begin{array}{l}\text { Свыше } 3 \text { тонн зерна на } \\
\text { душу населения }\end{array}$ & $\begin{array}{l}\text { Орловская область (4147), Курская область (3900 кг), Ставропольский край } \\
\text { (3655), Тамбовская область (3125). }\end{array}$ \\
\hline $\begin{array}{l}\text { От } 2 \text { до } 3 \text { тонн зерна на } \\
\text { душу населения }\end{array}$ & $\begin{array}{l}\text { Ростовская область (2741), Краснодарский край (2509), Липецкая область (2489), } \\
\text { Белгородская область (2257), Курганская область (2123), Воронежская область } \\
\text { (2063), Алтайский край (2041). }\end{array}$ \\
\hline $\begin{array}{l}\text { От 1 до 2 тонн зерна на } \\
\text { душу населения }\end{array}$ & $\begin{array}{l}\text { Республика Калмыкия (1799), Волгоградская область (1785), Саратовская об- } \\
\text { ласть (1718), Омская область (1656), Оренбургская область (1575), Республика } \\
\text { Адыгея (1541), Республика Мордовия (1476), Пензенская область (1449), Рязан- } \\
\text { ская область (1380), Кабардино-Балкарская Республика (1330), Брянская область } \\
\text { (1179), Республика Татарстан (1057), Тульская область (1037), Карачаево-Черкес- } \\
\text { ская Республика (1012). }\end{array}$ \\
\hline
\end{tabular}

Источник. Составлено автором на основе данных статистического сборника Регионы России [3] 
зерна на фуражные цели для сокращения его нерационального использования и обеспечения наращивания производства животноводческой продукции в рамках импортозамещения продовольствия;

- стимулировать развитие внутреннего рынка потребления зерна, в первую очередь, за счет роста спроса на зерно как важного элемента кормовой базы, способствующей обеспечению продовольственной безопасности по продукции животноводства;

- совершенствовать межотраслевые пропорции и межрегиональный обмен, для вырав- нивания финансовых условий для непосредственных производителей зерна;

- развивать логистические системы, определяющие состояние инфраструктуры зернового рынка страны для целей роста внутреннего потребления и увеличения экспортных потоков зерна;

- создавать условия для регулирования переизбытка предложения зерна на внутреннем рынке за счет санации через экспорт, выравнивая финансовые условия продажи зерна на внутреннем и мировом рынках.

\section{Библиографический список}

1. Алтухов А.И. Роль территориально-отраслевого разделения труда в агропромышленном производстве страны в обеспечении продовольственной независимости // Региональный вестник. 2015. № 1. С. 2-7.

2. Жилин В.В. Технология подборки факторов в модель регрессии / В.В. Жилин, С.Д. Майкова, Н.А. Пожидаева //Региональный вестник. 2016. № 4. С. 12-13.

3. Регионы России. Социально-экономические показатели. 2017 // Стат. сб. Москва. 2017. 1402 с.

4. Соловьева Т.Н. Государственное регулирование и импортозамещение продовольственной продукции: проблемы и решения / Т.Н. Соловьева, Н.А. Пожидаева, Д.А. Зюкин // Экономика сельскохозяйственных и перерабатывающих предприятий. 2016. № 11. С. 17-20.

5. Беляев С.А., Бобровский Е.А., Бушина Н.С. и др. Теория и практика применения корреляционно-регрессионного анализа в исследованиях: монография / Под общей редакцией В.В. Жилина. Курск. 2016. 80 с. 